\title{
N-Methyl-D-Aspartate Receptor and Neuronal Nitric Oxide Synthase Activation Mediate Bilirubin-Induced Neurotoxicity
}

\author{
Maria A Brito, * Ana R Vaz, * Sandra L Silva, Ana S Falcão, Adelaide Fernandes, Rui FM Silva, \\ and Dora Brites
}

Research Institute for Medicines and Pharmaceutical Sciences (iMed.UL), Faculdade de Farmácia, University of Lisbon, Lisbon, Portugal

\begin{abstract}
Hyperbilirubinemia may lead to neurotoxicity and neuronal death. Although the mechanisms of nerve cell damage by unconjugated bilirubin (UCB) appear to involve a disruption of the redox status and excitotoxicity, the contribution of nitric oxide (NO.) and of $\mathrm{N}$-methyl-D-aspartate (NMDA) glutamate receptors is unclear. We investigated the role of NO. and NMDA glutamate receptors in the pathways of nerve cell demise by UCB. Neurons were incubated with $100 \mu \mathrm{mol} / \mathrm{L}$ UCB, in the presence of $100 \mu \mathrm{mol} / \mathrm{L}$ human serum albumin for $4 \mathrm{~h}$ at $37^{\circ} \mathrm{C}$, alone or in combination with $\mathrm{N}$ - $\omega$-nitro-L-arginine methyl ester (L-NAME) (an inhibitor of neuronal nitric oxide synthase (nNOS)), hemoglobin (an NO. scavenger) or (+)-5-methyl-10,1 1-dihydro-5H-dibenzo(a,d)cyclohepten5, 10-imine maleate (MK-801) (an NMDA-receptor antagonist). Exposure to UCB led to increased expression of nNOS and production of both NO. and cyclic guanosine 3',5'-monophosphate (cGMP), along with protein oxidation and depletion of glutathione. These events concurred for cell dysfunction and death and were counteracted by L-NAME. Moreover, the UCB-induced loss of neuronal viability was abolished by hemoglobin, whereas the activation of nNOS and production of both NO. and cGMP were counteracted by MK-801, resulting in significant protection from cell dysfunction and death. These results reinforce the involvement of oxidative stress by showing that nerve cell damage by UCB is mediated by NO. and therefore is counteracted by NO. inhibitors or scavengers. Our findings strongly suggest that the activation of nNOS and neurotoxicity occur through the engagement of NMDA receptors. These data reveal a role for overstimulation of glutamate receptors in mediating oxidative damage by UCB.
\end{abstract}

(c) 2010 The Feinstein Institute for Medical Research, www.feinsteininstitute.org

Online address: http://www.molmed.org

doi: 10.2119/molmed.2009.00152

\section{INTRODUCTION}

Oxidative stress occurs when the production of reactive oxygen and/or nitrogen species overwhelms the antioxidant defense capacity (1). Among the reactive nitrogen species is nitric oxide (NO·), a free radical formed by a group of constitutive and inducible nitric oxide synthase (NOS) enzymes (2). In neurons, $\mathrm{NO}$. synthesis occurs in a complex sequence of events involving the stimulation of glutamate receptors in the postsynaptic neuron, especially the $N$-methyl-D-aspartate (NMDA) subtype, which leads to increased intracellular free $\mathrm{Ca}^{2+}$ that, upon binding to calmodulin, activates neuronal NOS (nNOS), originating $\mathrm{NO} \cdot$ and L-citrulline from L-arginine and oxygen $(3,4)$.

One of the most biologically relevant actions of NO is its binding to the heme moiety in the heterodimeric enzyme, soluble guanylate cyclase (sGC). Activation of sGC by NO . results in the production of the second messenger molecule, $3^{\prime}, 5^{\prime}$ cyclic guanosine monophosphate (cGMP), which can regulate numerous physiological events such as vasodilatation and neurotransmission $(5,6)$.

Under certain pathological conditions, nNOS activation may be exacerbated owing to excessive activation of NMDA receptors, a process called excitotoxicity. The excess NO formed can permeate

*MAB and ARV contributed equally to this paper.

Address correspondence and reprint requests to Maria Alexandra Brito, Faculdade de Farmácia da Universidade de Lisboa, Av. Prof. Gama Pinto, 1649-003 Lisboa, Portugal.

Phone: +351 217946400; Fax: +351 217946491; E-mail: abrito@ff.ul.pt.

Submitted October 21, 2009; Accepted for publication June 28, 2010; Epub

(www.molmed.org) ahead of print June 30, 2010.

cell membranes and diffuse a distance of a few cell diameters from its site of synthesis to neighboring cells (3); it can impair numerous biological events by reacting with various metals, thiols and oxygen species, modifying proteins, DNA and lipids, therefore inducing neurotoxicity and playing a role in neurodegeneration (7). NO- mediates the toxicity of glutamate in primary cortical cultures and in a variety of model systems (8-10). At the subcellular level, $\mathrm{NO} \cdot$ leads to mitochondrial dysfunction and consequent energy deficiency that may constitute a driving pathway to neurodegeneration (11).

Unconjugated bilirubin (UCB) is an endogenous compound that at low concentrations can be beneficial owing to its antioxidant properties, whereas at higher levels it can induce cytotoxicity, particularly to the central nervous system (12). Toxic effects by UCB include the disruption of cell membrane structure and dynamic properties (13-15), as well as alter- 
ations in membrane potential, transport and enzymatic systems (16-19). The extracellular accumulation of glutamate that occurs because of impaired uptake and / or enhanced secretion (20-23) indicates that UCB prolongs the presence of glutamate in the synaptic cleft. Moreover, the activation of NMDA receptors found in developing rat brain neurons exposed to UCB $(24,25)$, together with the association between jaundice and damage in Gunn rats (26), point to excitotoxicity as a key player in UCB neurotoxicity.

We have been compiling evidence that oxidative stress is involved in the mechanisms of UCB cytotoxicity. Blood samples from moderately jaundiced neonates present higher levels of membrane-bound hemoglobin $(12,27)$, an indicator of oxidative stress (28). Studies by spin-labeling electron paramagnetic resonance spectroscopy analysis indicated that UCB disrupts the redox status of isolated mitochondria (14), intact nerve cells (15) and dipalmitoyl phosphatidylcholine liposomes (unpublished observations). Moreover, injury to neocortical synaptosomes was linked to a disruption of the redox status (18), also observed in primary cultures of neurons $(29,30)$. More recently, we demonstrated that deregulation of energy metabolism is also involved in UCB-induced oxidative injury to immature neurons (31). However, the contributions of NO- as well as of NMDA receptors in the neuronal oxidative lesion by UCB are still unclear. We evaluated the effects of UCB on the redox status of rat cortical neurons and investigated the role of $\mathrm{NO}$ - and NMDA glutamate receptors in UCB neurotoxicity.

\section{MATERIALS AND METHODS}

\section{Chemicals}

Neurobasal medium, B-27 supplement (50x), Hanks' balanced salt solution (HBSS-1), HBSS without $\mathrm{Ca}^{2+}$ and $\mathrm{Mg}^{2+}$ (HBSS-2), gentamicin (50 mg/mL) and trypsin $(0.025 \%)$ were purchased from Invitrogen (Carlsbad, CA, USA). Fetal calf serum was obtained from Biochrom AG (Berlin, Germany). Antibiotic antimycotic solution (20x), human serum albumin
(HSA) (fraction V, fatty acid free), reduced and oxidized glutathione (GSH), $N$-1-naphthylethylenediamine, $N-\omega$ nitro-L-arginine methyl ester (L-NAME), (+)-5-methyl-10,11-dihydro-5Hdibenzo[a,d]cyclohepten-5,10-imine maleate (MK-801), hemoglobin, primary monoclonal antibody mouse anti- $\beta$-actin, alkaline phosphatase-labeled antirabbit IgG secondary antibody, Sigma Fast Tablets, and 1-isobutyl-3-methylxanthine and 3-(4,5-dimethylthiazol, 2-yl)-2,5diphenyltetrazolium bromide (MTT) were from Sigma Chemical (St Louis, MO, USA). UCB was also acquired from Sigma and purified according to the method of McDonagh (32). The primary specific monoclonal antibody, mouse antinNOS, was acquired from BD Biosciences (Erembodegem, Belgium). Horseradish peroxidase-labeled rabbit antigoat IgG was from Santa Cruz Biotechnology (Santa Cruz, CA, USA). Horseradish peroxidase-labeled sheep antimouse IgG, nitrocellulose membrane and Hyperfilm ECL for Western blot were from GE Healtchcare (Freiburg, Germany). Cell lysis buffer and LumiGLO ${ }^{\circledR}$ were acquired from Cell Signaling (Beverly, MA, USA). Slot blotting materials, including apparatus, nitrocellulose membranes and transfer filter papers, were from Bio-Rad (Hercules, CA, USA) in addition to the protein assay (Bio-Rad Laboratories $\mathrm{GmbH}$, Munich, Germany). The OxyBlot kit used for protein carbonyl determination was from Chemicon (Temecula, CA, USA). Lactate dehydrogenase (LDH) release by nonviable cells was assessed by using the Cytotoxicity Detection Kit (LDH) from Roche Molecular Biochemicals (Manheim, Germany). A cyclic GMP enzyme immunoassay kit was from Enzo Life Sciences (Plymouth Meeting, PA, USA). All other chemicals were of analytical grade and were purchased from Merck (Darmstadt, Germany).

\section{Neuron Primary Cultures}

Animal care was performed according to the recommendations of the European Convention for the Protection of Vertebrate Animals Used for Experimental and Other Scientific Purposes (Council Directive 86/609/EEC) and National Law 1005/92 (rules for protection of experimental animals). All animal procedures were approved by the institutional animal care and use committee. Every effort was made to minimize the number of animals used and their suffering.

Neuronal cell cultures were prepared from the cerebrum cortical region of Wistar rats, and neurons were isolated from fetuses from pregnant rats at 17-18 d gestation, as previously described (21). Cells were morphologically characterized by phase-contrast microscopy and used after $8 \mathrm{~d}$ in vitro. Our cell culture protocol avoided contamination by glial cells (33), which was lower than $1 \%$ as assessed by immunocytochemical staining with primary antibodies raised against glial fibrillary acidic protein of astrocytes.

\section{Neuron Treatment}

A 100-mmol/L stock solution of L-NAME, a competitive NOS inhibitor (4), a 200- $\mu \mathrm{mol} / \mathrm{L}$ stock solution of hemoglobin, an NO- scavenger (3), and a 1-mmol / L stock solution of MK-801, an NMDA receptor antagonist (26), were prepared in phosphate-buffered saline (PBS), pH 7.4. A stock solution of purified UCB was prepared in $0.1 \mathrm{~N} \mathrm{NaOH}$ immediately before use, and the $\mathrm{pH}$ of the incubation medium was restored to 7.4 by addition of equivalent amounts of $0.1 \mathrm{~N} \mathrm{HCl}$. All the experiments with UCB were performed under light protection to avoid photodegradation.

Incubation conditions with UCB were selected based on results of our previous studies $(29,34)$, in which we used the UCB concentrations of 50 and $100 \mu \mathrm{mol} / \mathrm{L}$ in the presence of HSA, which corresponded to UCB / HSA molar ratios of 0.5 and 1.0, respectively. The $100 \mu \mathrm{mol} / \mathrm{L}$ concentration has been shown to repeatedly induce more consistent results with differentiated neurons (34). Thus, in the present study we used the UCB/HSA molar ratio of 1.0 to assess whether the effects produced by UCB could be prevented, which we expected to be more evidently shown under these conditions. Higher UCB concentra- 
tions and UCB / HSA molar ratios were avoided by us because of colloidal formation followed by UCB precipitation. We selected a 4-h incubation period because results of our previous studies (12) demonstrated that 4-h incubation produced a statistically significant increase in LDH release but did not cause excessive cell death by UCB, which would compromise the assessment of functional indicators such as nNOS. Therefore, neurons were treated with $100 \mu \mathrm{mol} / \mathrm{L} \mathrm{UCB}$, $100 \mu \mathrm{mol} / \mathrm{L}$ L-NAME, UCB plus L-NAME or no addition (control) in the presence of $100 \mu \mathrm{mol} / \mathrm{L} \mathrm{HSA}$ for $4 \mathrm{~h}$ at $37^{\circ} \mathrm{C}$. Other sets of experiments were performed in which cells were incubated with UCB alone or in combination with $2 \mu \mathrm{mol} / \mathrm{L}$ hemoglobin, or with $1 \mu \mathrm{mol} / \mathrm{L}$ MK-801 (added $1 \mathrm{~h}$ prior to UCB addition).

After treatment, attached cells were collected and evaluated for nNOS expression, as well as for cGMP, protein oxidation and intracellular GSH levels. An MTT test was also performed on the cells, and the cell-free medium was used for measurement of concentrations of nitrites, glutamate and LDH.

\section{Evaluation of nNOS Expression}

The expression of nNOS was determined by Western blot analysis of cell extracts obtained by lysing cells in ice-cold lysis buffer: $10 \times[20 \mathrm{mmol} / \mathrm{L}$ Tris- $\mathrm{HCl}$ (pH 7.5), $150 \mathrm{mmol} / \mathrm{L} \mathrm{NaCl}, 1 \mathrm{mmol} / \mathrm{L}$ $\mathrm{Na}_{2}$ EDTA, $1 \mathrm{mmol} / \mathrm{L}$ EGTA, $1 \%$ Triton $\mathrm{X}-100,2.5 \mathrm{mmol} / \mathrm{L}$ sodium pyrophosphate, $1 \mathrm{mmol} / \mathrm{L} \beta$-glycerophosphate, $1 \mathrm{mmol} / \mathrm{L} \mathrm{Na}_{3} \mathrm{VO}_{4}, 1 \mu \mathrm{g} / \mathrm{mL}$ leupeptin, $1 \mathrm{mmol} / \mathrm{L}$ phenylmethylsulfonyl fluoride]. Cells were kept in lysis buffer on ice for $5 \mathrm{~min}$ and sonicated for $20 \mathrm{~s}$. The lysate was centrifuged at $14,000 \mathrm{~g}$ for $10 \mathrm{~min}$ at $4^{\circ} \mathrm{C}$; supernatants were collected and protein content was determined by use of a protein assay reagent. Equal amounts of protein were subjected to sodium dodecyl sulphate-polyacrylamide gel electrophoresis and transferred to a nitrocellulose membrane. Membranes were washed with Tris-buffered saline (TBS) (20 mmol/L Tris-HCl [pH 7.6], and $137 \mathrm{mmol} / \mathrm{L} \mathrm{NaCl}$ ] and blocked for $1 \mathrm{~h}$ at room temperature in blocking buffer (TBS containing $0.1 \%$ [v/v] Tween-20 [T-TBS] plus 5\% [w/v] nonfat dried milk). Membranes were washed 3 times with T-TBS and incubated with primary antibody (anti-nNOS [1:2500] or anti- $\beta$-actin [1:10000] in TBS containing 5\% [w/v] bovine serum albumin) overnight at $4^{\circ} \mathrm{C}$. After 3 washes in T-TBS, the membranes were incubated with horseradish peroxidase-labeled secondary antibody (antimouse [1:5000] in blocking buffer) for $1 \mathrm{~h}$ at room temperature. Protein bands were detected by LumiGLO and visualized by using the ChemiDoc XRS (Bio-Rad) scanner or by autoradiography with Hyperfilm ECL. The relative intensities of protein bands were analyzed by using the Quantity One (version 4.6.5) program (Bio-Rad Laboratories).

\section{Quantification of Nitrite Levels}

The activity of nNOS was further assessed by determination of nitrite $\left(\mathrm{NO}_{2}{ }^{-}\right)$, a stable product of $\mathrm{NO} \cdot$, in the incubation medium. Nitrite levels were quantified by Griess reaction (35), at $\lambda=540$ $\mathrm{nm}$ with a reference filter of $620 \mathrm{~nm}$ in a microplate reader (Bio-Rad Laboratories, Hemel Hempstead, UK). Solutions of sodium nitrite $(0-200 \mu \mathrm{mol} / \mathrm{L})$ were used as standards.

\section{Measurement of cGMP Concentrations}

The synthesis of NO . can be determined either by measuring its breakdown product, nitrite, or by measuring its ability to stimulate sGC, leading to cGMP production (4). For quantification of cGMP content, the phosphodiesterase inhibitor 1-isobutyl-3-methylxanthine was included in the incubation medium. Cell extracts collected from $9.6 \mathrm{~cm}^{2}$ wells were used for cGMP determination by use of the commercially available kit from Enzo Life Sciences, and measurements were performed according to manufacturer's instructions.

\section{Assessment of Protein Oxidation}

Protein-resident carbonyls were measured as a marker of oxidative stress by slot blot analysis of the 2,4-dinitrophenylhydrazone adducts of the carbonyls formed by reaction with 2,4-dinitrophenylhydrazine. At the end of incubation, cells were rinsed with icecold PBS and harvested by scraping into PBS. The cell suspension was sonicated and formation of carbonyls was quantified using the OxyBlot kit, as previously described $(29,30)$.

\section{GSH Determination}

GSH levels were calculated from those of total GSH (GSt) and oxidized GSH $(\mathrm{GSSG}): \mathrm{GSt}=\mathrm{GSH}+(2 \times \mathrm{GSSG}) \cdot \mathrm{GSt}$ was determined by an enzymatic recycling procedure, and GSSG was determined after derivatization of GSH by reaction with 2-vinylpyridine, as previously described (29).

\section{Assessment of Cell Function}

Cellular reduction of MTT was measured in neurons, as we have previously described (21). Briefly, after the incubation period, neurons were incubated for $1 \mathrm{~h}$ at $37^{\circ} \mathrm{C}$ with $500 \mu \mathrm{L}$ of MTT at $0.5 \mathrm{mg} / \mathrm{mL}$, prepared by dilution of a freshly prepared stock solution at $5 \mathrm{mg} / \mathrm{mL}$ in Neurobasal medium. After incubation, medium was discarded and MTT formazan crystals were dissolved by addition of $1 \mathrm{~mL}$ isopropanol $/ \mathrm{HCl} 0.04 \mathrm{~mol} / \mathrm{L}$ and gentle shaking for $15 \mathrm{~min}$, at room temperature. After centrifugation, absorbance values at $570 \mathrm{~nm}$ were determined in a Unicam UV2 spectrophotometer (Unicam Limited, UV2, Cambridge, UK). Results were expressed as percentage of control, which was considered as $100 \%$.

\section{Cytotoxicity Evaluation}

We measured LDH release by cells with a disrupted membrane as a tool to ascertain the extent of cell death. $\mathrm{LDH}$ activity was quantified in the incubation medium by using the Cytotoxicity Detection Kit (LDH), as previously described $(29,30)$. The results were expressed as percentage of total LDH release, obtained by lysing nonincubated cells with 2\% Triton X-100 in Neurobasal medium for $30 \mathrm{~min}$. 
A
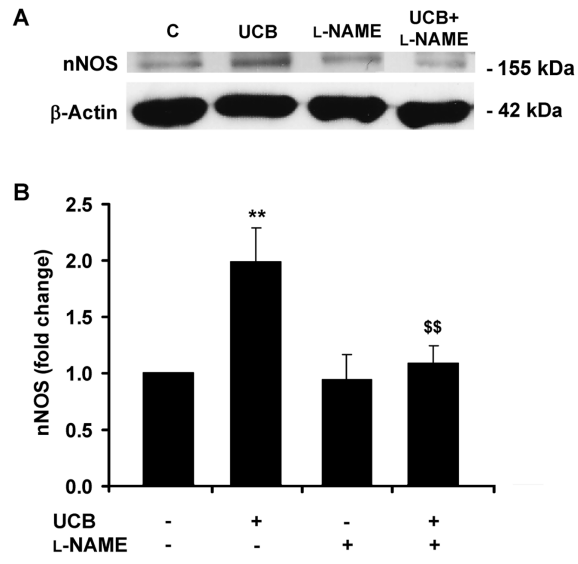

Figure 1. UCB induces neuronal nNOS expression in neurons, which is counteracted by L-NAME. Primary cultures of rat neurons were treated for $4 \mathrm{~h}$ at $37^{\circ} \mathrm{C}$ with either $100 \mu \mathrm{mol} / \mathrm{L}$ UCB, $100 \mu \mathrm{mol} / \mathrm{L}$ L-NAME, UCB plus L-NAME or no addition (control), in the presence of $100 \mu \mathrm{mol} / \mathrm{L}$ HSA. The expression of nNOS was evaluated by Western blotting, as described in Materials and Methods. (A) Blot representative of at least four separate experiments. (B) The intensity of the bands was quantified by scanning densitometry, normalized with respect to endogenous $\beta$-actin and expressed as fold change compared with control. ${ }^{* *} P<0.01$ from control; ${ }^{\$ \$} P<0.01$ from UCB alone.

\section{Statistical Analysis}

Results are expressed as means \pm SEM from at least four separate experiments performed in duplicate. Differences between groups were determined by oneway ANOVA with Bonferroni's multiple comparisons post test, using Instat 3.05 (GraphPad Software, San Diego, CA). Statistical significance was considered when $P$ values were lower than 0.05 .

\section{RESULTS}

\section{UCB Enhances nNOS Expression in Neurons}

We started by investigating whether UCB upregulates nNOS in primary cultures of rat neurons by assessing the enzyme expression by Western blot (Figure 1). Incubation of neurons with UCB increased $\mathrm{nNOS}$ protein expression by two-fold $(P<0.01)$. Because L-NAME is known to inhibit NOS activity in an enan- tiomerically specific manner (4), we evaluated whether it prevented the enzyme stimulation by UCB. In fact, when $100 \mu \mathrm{mol} / \mathrm{L} \mathrm{L}-\mathrm{NAME}$ was associated with UCB the values returned to levels similar to those observed in controls (1.1-fold, not significant), indicating that UCB-induced increased expression of nNOS was blocked by approximately $90 \%(P<0.01)$. These data demonstrate that UCB at pathophysiologically relevant concentrations induces the expression of nNOS.

\section{UCB Promotes Nitrite Production by Neurons}

We further evaluated nitrite production, an index of NO formation, following exposure to UCB. As shown in Figure 2, UCB induced a 2.4-fold $(P<0.01)$ increase in nitrite levels, whereas cotreatment of neurons with L-NAME significantly reversed the UCB-induced effect by $75 \%(P<0.01)$. Therefore, UCB induces the production of nitrite by neurons, suggesting that UCB-induced neurotoxicity is mediated, at least in part, by NO. production.

\section{UCB Leads to Increased cGMP Production by Neurons}

To confirm the augmented synthesis of $\mathrm{NO}$ - in UCB-exposed neurons, we determined cGMP, the resulting product of sGC stimulation by NO (4). As represented in Figure 3, cGMP levels increased from $13.5 \pm 1.5 \mathrm{pmol} / \mathrm{mg}$ in controls to $22.6 \pm 1.9 \mathrm{pmol} / \mathrm{mg}$ protein in UCBtreated samples $(P<0.01)$ and returned to nearly basal values $(15.3 \pm 2.1 \mathrm{pmol} / \mathrm{mg})$ after treatment with UCB in the presence of L-NAME ( $P<0.05$ from UCB alone).

These results sustain our hypothesis that $\mathrm{NO} \cdot$ production occurs during neuronal exposure to UCB.

\section{NO. Is Involved in Protein Oxidation Induced by UCB}

To clarify whether oxidation of cell components occurs in the conditions used in the present study, measurement of protein carbonyls was selected as a tool to assess the extent of protein oxidation. UCB caused a $24 \%(P<0.01)$ in-

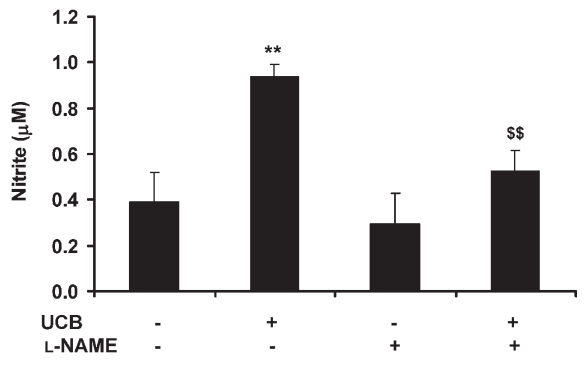

Figure 2. UCB induces nitrite formation in neurons, which is abrogated by L-NAME. Primary cultures of rat neurons were treated for $4 \mathrm{~h}$ at $37^{\circ} \mathrm{C}$ with $100 \mu \mathrm{mol} / \mathrm{L}$ UCB, $100 \mu \mathrm{mol} / \mathrm{L}$ L-NAME, UCB plus L-NAME or no addition (control), in the presence of $100 \mu \mathrm{mol} / \mathrm{L} \mathrm{HSA}$. The formation of NO. was indirectly evaluated by measuring nitrites in the incubation medium using the Griess reagent, as described in Materials and Methods. ${ }^{* *} P<0.01$ from control; ${ }^{\$ \$} P<0.01$ from UCB alone.

crease in the formation of protein carbonyls (Figure 4) pointing to the oxidation of cellular proteins by UCB. To determine the role of $\mathrm{NO}$ - in this process, we assessed protein carbonyls levels when both UCB and L-NAME were present. We observed that carbonyls decreased $(P<$ 0.05 from UCB alone), which indicated a nearly $70 \%$ protection against protein oxi-

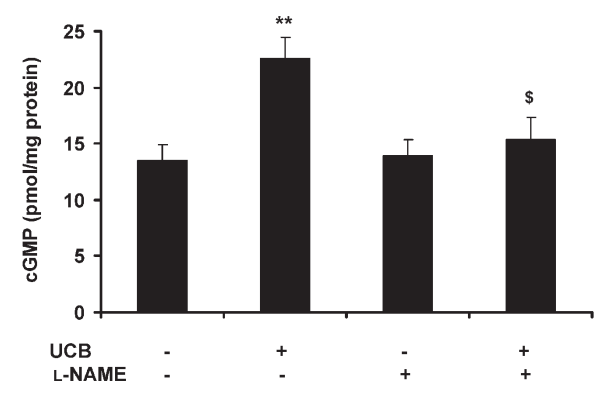

Figure 3. UCB induces CGMP production in neurons, which is prevented by L-NAME. Primary cultures of rat neurons were treated for $4 \mathrm{~h}$ at $37^{\circ} \mathrm{C}$ with $100 \mu \mathrm{mol} / \mathrm{L}$ UCB, $100 \mu \mathrm{mol} / \mathrm{L}$ L-NAME, UCB plus L-NAME or no addition (control), in the presence of $100 \mu \mathrm{mol} / \mathrm{L}$ HSA. Formation of cGMP was assessed by using a commercial kit, as described in Materials and Methods. ${ }^{* *} P<$ 0.01 from control; ${ }^{\$} P<0.05$ from UCB alone. 


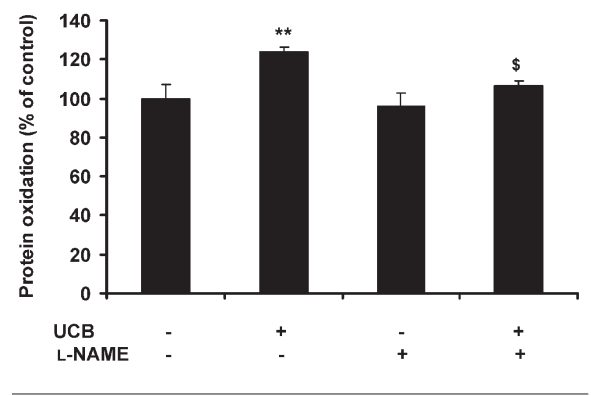

Figure 4. UCB induces protein oxidation in neurons, which is prevented by L-NAME. Primary cultures of rat neurons were treated for $4 \mathrm{~h}$ at $37^{\circ} \mathrm{C}$ with either $100 \mu \mathrm{mol} / L$ UCB, $100 \mu \mathrm{mol} / \mathrm{L}$ L-NAME, UCB plus L-NAME or no addition (control), in the presence of 100 $\mu \mathrm{mol} / \mathrm{L}$ HSA. Protein oxidation was assessed by quantification of carbonyls by slot blot analysis, as described in Materials and Methods. ${ }^{* *} P<0.01$ from control; ${ }^{\$} P<$ 0.05 from UCB alone.

dation induced by UCB. These results, showing that L-NAME significantly counteracts the oxidative effect of $\mathrm{UCB}$, indicate that NO. is involved in oxidative injury of neuronal proteins.

\section{NO. Is Involved in the Disruption of GSH Homeostasis Induced by UCB}

Having established that UCB promotes oxidative injury to neuronal proteins, we considered of relevance to look for alterations in the cellular antioxidant defense mechanisms following exposure to UCB. We evaluated the intracellular levels of GSH, a low molecular weight thiol with important functions as an antioxidant (36). Treatment of nerve cells with UCB caused a nearly $20 \%$ decrease in GSH levels, from $\sim 13 \mathrm{nmol} / \mathrm{mg}$ protein in control assays to $\sim 10 \mathrm{nmol} / \mathrm{mg}$ protein in UCB-treated samples $(P<0.05)$ (Figure 5$)$. The levels of GSH in control assays accounted for $93 \%$ of GSt, which also decreased by approximately $20 \%$ after incubation with UCB (13.9 \pm 0.8 versus $11.6 \pm 0.9 \mathrm{nmol} / \mathrm{mg}$ protein, $P<0.05)$. These results show that UCB leads to consumption of antioxidant defenses and that disruption of GSH homeostasis takes place upon neuronal exposure to UCB.

To ascertain whether NO- is involved in the depletion of cellular GSH, sister

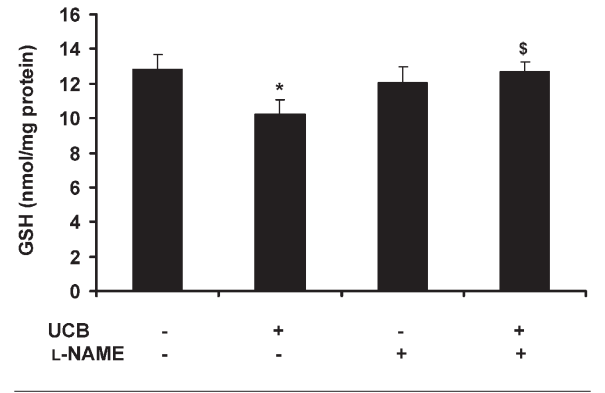

Figure 5. UCB impairs GSH homeostasis in neurons, which is restored by L-NAME. Primary cultures of rat neurons were treated for $4 \mathrm{~h}$ at $37^{\circ} \mathrm{C}$ with $100 \mu \mathrm{mol} / \mathrm{L}$ UCB, $100 \mu \mathrm{mol} / \mathrm{L}$ L-NAME, UCB plus L-NAME or no addition (control), in the presence of $100 \mu \mathrm{mol} / \mathrm{L}$ HSA. Intracellular levels of reduced GSH were determined by an enzymatic recycling procedure, as described in Materials and Methods. ${ }^{*} P<0.05$ from control; ${ }^{\$} P<0.05$ from UCB alone.

experiments were performed in the presence of L-NAME. In the presence of the nNOS inhibitor, the disruption of GSH homeostasis induced by UCB was abrogated, as indicated by the GSH levels of $12.7 \pm 0.6 \mathrm{nmol} / \mathrm{mg}$ protein $(P<0.05$ from UCB alone), which were very close to those observed either with L-NAME alone or in control experiments (Figure 5). These results, showing that L-NAME prevents the consumption of GSH stores by UCB, reinforce the concept that NO- plays a role in the oxidative disruption of neuronal cells resulting from UCB interaction.

\section{NO. Is Engaged in UCB-Induced Neuronal Dysfunction}

To assess the effect of UCB on neuronal function, we performed the MTT test after the incubation period. Cell dysfunction in UCB-treated neurons was remarkable (Figure 6), as indicated by a more than $50 \%$ decrease in the ability to reduce MTT $(P<0.01)$. Incubation with UCB and L-NAME partially abrogated cell dysfunction, as indicated by the increase in MTT reduction levels, from $\sim 47 \%$ in UCB-treated samples to $\sim 72 \%$ in those exposed to UCB in the presence of the nNOS inhibitor $(P<0.01)$. By showing that abolishment of NO . production

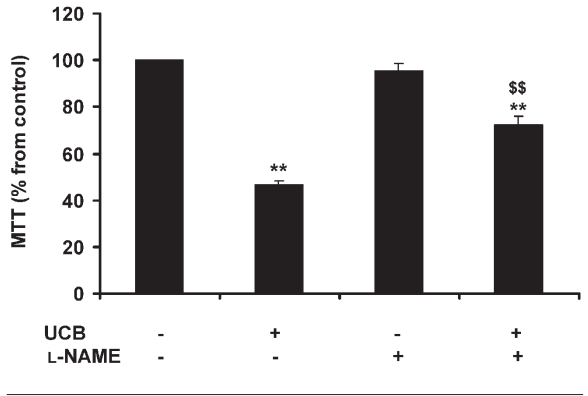

Figure 6. UCB impairs cell function in neurons, which is restored by L-NAME. Primary cultures of rat neurons were treated for $4 \mathrm{~h}$ at $37^{\circ} \mathrm{C}$ with either $100 \mu \mathrm{mol} / \mathrm{L}$ UCB,

$100 \mu \mathrm{mol} / \mathrm{L}$ L-NAME, UCB plus L-NAME or no addition (control), in the presence of 100 $\mu \mathrm{mol} / \mathrm{L} \mathrm{HSA}$. Cell function was assessed by measurement of MTT conversion to a blue formazan product, as described in Materials and Methods. ${ }^{* *} P<0.01$ from control; ${ }^{\$} P<0.05$ from UCB alone.

improves MTT metabolism, these results further point to the involvement of this reactive species in neuronal impairment by UCB.

\section{NO. Is Implicated in Neuronal Death Induced by UCB}

To evaluate whether NO is involved in UCB-induced neurotoxicity, we measured the release of LDH by cells with a disrupted membrane, a characteristic attribute of necrosis/ oncosis. We obtained a 1.8-fold $(P<0.01)$ increase in LDH release by neurons exposed to UCB (Figure 7). However, the overall cell death did not surpass $10 \%$, confirming that our conditions were desirable to evaluate the roles of both nNOS and NO- in UCB-induced oxidative demise. Therefore, we next evaluated cell death after incubation with a combination of UCB and L-NAME. Interestingly, UCB-induced cell death was almost counteracted by the NOS inhibitor $(P<0.05)$, with values very closely resembling those obtained with L-NAME alone and in controls. These results provide further evidence for the role of NO- as an intervening molecule in the mechanisms of cell injury by UCB. In addition, a further corroboration was obtained by the nearly $80 \%$ protection achieved after neuronal 


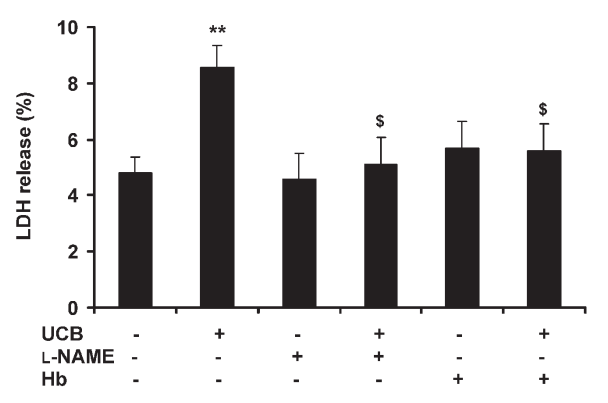

Figure 7. UCB induces neuronal death, which is prevented by L-NAME or by hemoglobin $(\mathrm{Hb})$. Primary cultures of rat neurons were treated for $4 \mathrm{~h}$ at $37^{\circ} \mathrm{C}$ with $100 \mu \mathrm{mol} / \mathrm{L}$ UCB, $100 \mu \mathrm{mol} / \mathrm{L}$ L-NAME, UCB plus L-NAME, $2 \mu \mathrm{mol} / \mathrm{L} \mathrm{Hb}$, UCB plus $\mathrm{Hb}$ or no addition (control), in the presence of $100 \mu \mathrm{mol} / \mathrm{L}$ HSA. Cell death was evaluated by measuring the activity of LDH released by nonviable cells to the incubation medium by using the LDH cytotoxicity detection kit, as described in Materials and Methods. ${ }^{* *} P<0.01$ from control; ${ }^{\$} P<0.05$ from UCB alone.

incubation with hemoglobin (Figure 7), a known NO- scavenger (3). These data, together with those from the MTT test, support the notion that NO- is implicated in neuronal injury by UCB.

\section{Overstimulation of NMDA Receptors Mediates UCB-Induced Expression of nNOS and Neurotoxicity}

Having established that NO- intervenes in UCB-induced neuronal injury, we wondered whether the disruption of the redox status was a primary event or was secondary to the UCB-induced extracellular accumulation of glutamate $(21,22)$. Thus, we investigated whether the presence of MK-801, a NMDA glutamatesubtype receptor antagonist, was able to prevent the expression of nNOS and cytotoxicity. Levels of glutamate in the extracellular medium were also determined after treatment with UCB and MK-801, alone or in combination. As indicated in Table 1, MK-801 prevented UCB-induced expression of $\mathrm{nNOS}$ and the consequent increased production of nitrites and of cGMP $(P<0.05, P<0.01$ and $P<0.05$ from UCB alone, respectively) by at least $80 \%$. Neuronal functionality and viability

Table 1. MK-801 abrogates UCB-induced nNOS overexpression, nitrite formation, CGMP production, MTT reduction impairment and LDH release, but not extracellular glutamate accumulation. $^{\text {a }}$

\begin{tabular}{lrrrr}
\hline & Control & \multicolumn{1}{c}{ UCB } & MK-801 & UCB + MK-801 \\
\hline Glutamate, $\mu \mathrm{mol} / \mathrm{L}$ & $7.02 \pm 0.76$ & $130.12 \pm 5.54^{\mathrm{b}}$ & $6.39 \pm 0.69$ & $121.71 \pm 5.76$ \\
nNOS, fold change & $1.00 \pm 0.00$ & $1.98 \pm 0.36^{\mathrm{b}}$ & $1.04 \pm 0.12$ & $1.13 \pm 0.23^{\mathrm{c}}$ \\
Nitrite, $\mu \mathrm{mol} / \mathrm{L}$ & $0.39 \pm 0.10$ & $0.94 \pm 0.12^{\mathrm{b}}$ & $0.49 \pm 0.08$ & $0.39 \pm 0.08^{\mathrm{d}}$ \\
CGMP, pmol/mg protein & $13.49 \pm 1.46$ & $22.58 \pm 1.89^{\mathrm{b}}$ & $15.88 \pm 1.41$ & $15.39 \pm 2.03^{\mathrm{c}}$ \\
MTT, \% & $100 \pm 0.00$ & $46.82 \pm 1.28^{\mathrm{b}}$ & $90.45 \pm 4.89$ & $64.99 \pm 3.93^{\mathrm{b}, \mathrm{d}}$ \\
$\mathrm{LDH} \%$ & $3.66 \pm 0.75$ & $8.55 \pm 0.80^{\mathrm{b}}$ & $3.89 \pm 0.75$ & $3.29 \pm 1.10^{\mathrm{d}}$ \\
\hline
\end{tabular}

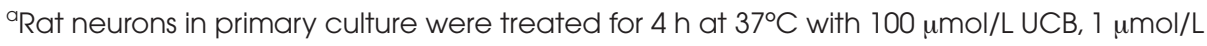
MK-801, UCB plus MK-801, or no addition (control), in the presence of $100 \mu \mathrm{mol} / \mathrm{L} \mathrm{HSA}$. Determinations of nNOS expression, as well as of nitrite, CGMP, LDH and glutamate levels, and MTT reduction test were performed as described in Materials and Methods.

${ }^{\mathrm{b}} P<0.01$ from control.

${ }^{c} P<0.05$ and ${ }^{d} P<0.01$ from UCB.

were also preserved $(P<0.01$ from UCB alone) after blockade of NMDA receptors as evidenced by the improvement of MTT metabolism and the levels of LDH release at the same magnitude of controls. In contrast, the elevated concentration of glutamate after incubation with UCB remained unchanged after coincubation with MK-801. These results indicate that UCB-induced oxidative stress and neuronal injury are, at least in part, mediated by overstimulation of NMDA receptors.

\section{DISCUSSION}

The results of the present study demonstrated that exposure of neurons to clinically relevant concentrations of UCB increases the expression of nNOS, as well as the production of nitrites and cGMP, which are accompanied by protein oxidation and cell demise, whereas the major cellular antioxidant defense system, provided by GSH, is impaired. In addition, the results showed that UCB-induced neuronal oxidative injury is prevented by NO synthesis inhibition or sequestration, as well as by blockade of NMDA receptor channels with MK801. These findings point to $\mathrm{NO} \cdot$ as a key mediator of UCB-induced oxidative disruption of neuronal cells and indicate that upregulation of $\mathrm{nNOS}$ and neurotoxicity occur through the engagement of NMDA receptors, suggesting that oxidative damage is secondary to over- stimulation of the glutamate receptors by UCB.

The imbalance between formation of oxidant species and consumption of the antioxidant defenses may be evaluated by oxidative stress biomarkers such as protein carbonyls, reliable indicators of protein oxidation, and GSH, which reflects the chain-breaking thiol antioxidant capacity of the cell $(36,37)$. By showing that exposure of neurons to UCB leads to protein oxidation, as well as to impairment of antioxidant defenses and cell viability, this study provides evidence for a causal relationship between UCB-induced oxidative stress and neuronal damage. The assumption that such a relationship exists is not without precedent, because UCB-induced oxidative injury has been shown to mediate cell death $(15,29,30)$, and a strong correlation between experimental obstructive jaundice and oxidative stress was found in the rat brain (38). Supplementation with the GSH precursor $\mathrm{N}$-acetylcysteine was shown to reverse the obstructive jaundice-induced oxidative stress in rats (38), as well as the oxidative injury resulting from exposure of rat neurons (30) and HeLa cells (39) to $\mathrm{UCB}$, findings that further reinforce the redox disruption as a cause of nerve cell impairment. These facts support our observation of a decrease in GSH and GSt levels by UCB that indicate the consumption of the tripeptide, probably in conjugation reactions catalyzed by GSH-S- 
transferase. This assumption is supported by the previously reported increase in the red cell enzyme in newborns with hyperbilirubinemia (40).

Neurons synthesize cGMP in response to NO by activation of sGC (5). Therefore, the increased levels of cGMP and nitrites observed in our study reflect the activation of the signaling pathway that triggers nNOS overexpression in UCB-treated neurons. The present observation that neuronal injury resulting from UCB interaction is mediated, at least in part, by NO. is sustained by the fact that there are several common pathways in NO-induced neurotoxicity (3) and UCB-induced neurotoxic manifestations, namely the increase in intracellular $\mathrm{Ca}^{2+}$ levels and the accumulation of extracellular glutamate, as well as the overstimulation of NMDA glutamate receptors, engendering excitotoxicity $(18,22,24,26,41)$. Moreover, $\mathrm{NO} \cdot$ is involved in inflammation (42), and there is evidence that UCB induces the release of the proinflammatory cytokine tumor necrosis factor $\alpha$ by neurons (22) and that the anti-inflammatory agent minocyline blocks UCB neurotoxicity $(43,44)$. In addition, NO· has important effects on mitochondria, leading to organelle dysfunction $(5,7,11)$, whereas this subcellular component has been regarded as a target of UCB cytotoxicity from the pioneer studies of Day (45) and of Ernster and Zetterström (46), until the current studies performed by us $(14,47)$. The mitochondrial constituent most sensitive to NO- is cytochrome $c$ oxidase, which was recently shown by us to be selectively inhibited by UCB in immature neurons (31). The consequent deregulation of energy status was also observed in UCB-treated neurons (31), which may constitute a pathway driving neurodegeneration.

The observations that increased formation of protein carbonyls and LDH release along with the decreased GSH stores and the diminished ability to reduce MTT are abrogated by pretreatment with L-NAME, which inhibits NOS activity, strongly indicate that neuronal oxidative stress induced by UCB is a process mediated by NOS and, consequently, by
$\mathrm{NO}$. A further corroboration is the finding of protection against cell death by coincubation with hemoglobin, which is considered as an NO. "sink," able to lower the NO . concentration (3).

Oxidative stress is usually associated with glutamate toxicity that can ultimately lead to cell death (48). As mentioned above, extracellular levels of glutamate increase after exposure of neurons to UCB. To test whether glutamate is a key mediator of NO-mediated neurotoxicity resulting from exposure to UCB, we used MK-801, an open-channel antagonist that can reach its binding site only when the channel is in an open state (41). MK-801 counteracted UCB-induced cell dysfunction and death, as well as overexpression of nNOS and the consequent release of $\mathrm{NO} \cdot$ and production of cGMP, indicating that the ion channel is in an open and activated state, leading to NMDA-receptor-mediated excitotoxicity and neuronal injury. These observations are in line with results of studies showing that UCB modifies the function of the NMDA receptor/ion channel complex in the brains of newborn piglets (41), that neuronal injury in the Gunn rat is reduced upon administration of MK-801 (26) and that cell death after incubation of human NT2-N neurons with UCB is prevented by the NMDA antagonist (49). Nevertheless, results of a recently published study (50) showed the absence of protection of UCB neurotoxicity by MK-801. These conflicting results may arise from the higher UCB-to-HSA molar ratio (2:1) used by these authors, leading to UCB precipitation at the membrane level, and the usage of neurons from the hippocampus, a region particularly affected during bilirubin encephalopathy. Because the NMDA receptor is vital to many important physiologic functions, its alterations during brain development may exert subtle effects that may not become apparent until the brain completely develops (41). Thus, our findings may provide a basis for the association between neonatal hyperbilirubinemia and neurologic deficits later in life $(51,52)$.

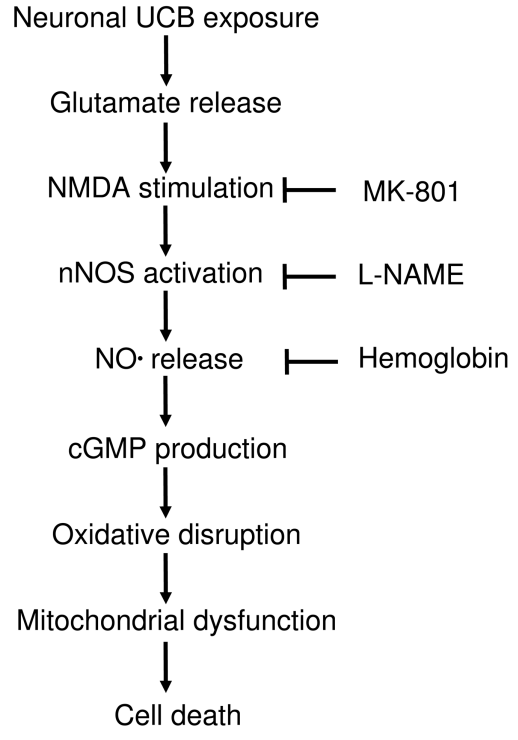

Figure 8. Schematic representation of key steps in neuronal oxidative damage by UCB. UCB interaction with neurons causes the release of the neurotransmitter glutamate, which stimulates the NMDA glutamate-subtype receptor. Upon stimulation of NMDA receptors, neuronal nNOS is activated and NO. is produced. NO. leads to increased formation of cGMP, through activation of soluble guanylate cyclase, and to disruption of the redox status. As a corollary of these events, mitochondrial function is impaired, ultimately leading to cell death. Inhibition of nNOS by L-NAME prevents downstream events from occurring, thus pointing to NO. as a key mediator in UCB-induced oxidative disruption. Preclusion of UCB-induced cell death by hemoglobin sequestration of NO. corroborates the involvement of this species in neuronal demise by UCB. Upstream blockade of NMDA receptors by MK-801 abrogates the neurotoxicity mediated by NO., therefore indicating that excitotoxicity plays a key role in UCB-induced oxidative damage to neurons.

Excitotoxicity driven by NMDAreceptor overstimulation gains increased relevance in UCB-induced encephalopathy when we consider our prior data showing an impairment of glutamate uptake by astrocytes exposed to UCB (20), as well as its increased release (23), which compromise brain glutamate homeostasis and favor neurodegenera- 
tion (53). In addition, we demonstrated that glutamate efflux from microglia increased by UCB (54) and its uptake is decreased in neurons incubated with UCB (21), further confirming the interference of UCB at the level of glutamate homeostasis.

Collectively, our data highlight some important steps in neuronal oxidative damage by UCB. As schematically represented in Figure 8, UCB interaction with neurons causes the release of the neurotransmitter glutamate. Upon stimulation of the NMDA glutamate-subtype receptors, nNOS is activated, NO- is produced and consequently cGMP is formed. The presence of $\mathrm{NO}$ - must account, at least in part, for the disruption of the redox status, which ultimately leads to cell function impairment and cell death. Inhibition of nNOS activity by L-NAME prevents downstream events from occurring, thus confirming that $\mathrm{NO}$ - is a key mediator of UCB-induced oxidative disruption. Upstream blockade of NMDA receptors by MK-801 abrogates neurotoxicity, confirming that excitotoxicity plays a key role in UCB-induced oxidative damage to neurons. Therefore, NOS inhibitors, as well as NMDA receptor antagonists, may be useful as therapeutic tools to reduce the risks associated with oxidative stress and neurotoxicity in unconjugated hyperbilirubinemia.

\section{ACKNOWLEDGMENTS}

This work was supported by grant PTDC/SAU-NEU / 64385/2006, from Fundação para a Ciência e a Tecnologia (FCT), Lisbon, Portugal, and European Regional Development Fund (FEDER) (to D Brites).

\section{DISCLOSURE}

The authors declare that they have no competing interests as defined by Molecular Medicine, or other interests that might be perceived to influence the results and discussion reported in this paper.

\section{REFERENCES}

1. Sies H. (1997) Oxidative stress: oxidants and antioxidants. Exp. Physiol. 82:291-5.
2. Knott AB, Bossy-Wetzel E. (2009) Nitric oxide in health and disease of the nervous system. Antioxid. Redox Signal. 11:1-13.

3. Ledo A, Frade J, Barbosa RM, Laranjinha J. (2004) Nitric oxide in brain: diffusion, targets and concentration dynamics in hippocampal subregions. Mol. Aspects Med. 25:75-89.

4. Knowles RG, Palacios M, Palmer RM, Moncada S. (1989) Formation of nitric oxide from L-arginine in the central nervous system: a transduction mechanism for stimulation of the soluble guanylate cyclase. Proc. Natl. Acad. Sci. U. S. A. 86:5159-62.

5. Moncada S, Bolaños JP. (2006) Nitric oxide, cell bioenergetics and neurodegeneration. J. Neurochem. 97:1676-89.

6. Krumenacker JS, Hanafy KA, Murad F. (2004) Regulation of nitric oxide and soluble guanylyl cyclase. Brain Res. Bull. 62:505-15.

7. Bolaños JP, Herrero-Mendez A, FernandezFernandez S, Almeida A. (2007) Linking glycolysis with oxidative stress in neural cells: a regulatory role for nitric oxide. Biochem. Soc, Trans. 35:1224-7.

8. Yun HY, Dawson VL, Dawson TM. (1999) Glutamate-stimulated calcium activation of Ras/Erk pathway mediated by nitric oxide. Diabetes Res. Clin. Pract. 45:113-5.

9. Bal-Price A, Brown GC. (2001) Inflammatory neurodegeneration mediated by nitric oxide from activated glia-inhibiting neuronal respiration, causing glutamate release and excitotoxicity. J. Neurosci. 21:6480-91.

10. Takahata K, et al. (2003) Retinal neurotoxicity of nitric oxide donors with different half-life of nitric oxide release: involvement of N-methyl-Daspartate receptor. J. Pharmacol. Sci. 92:428-32.

11. Bolaños JP, Delgado-Esteban M, Herrero-Mendez A, Fernandez-Fernandez S, Almeida A. (2008) Regulation of glycolysis and pentose-phosphate pathway by nitric oxide: impact on neuronal survival. Biochim. Biophys. Acta. 1777:789-93.

12. Brito MA, Silva RFM, Brites D. (2006) Cell response to hyperbilirubinemia: a journey along key molecular events. In: New Trends in Brain Research. Chen FJ (ed.) Nova Science Publishers, New York, pp.1-38.

13. Brito MA, Silva R, Tiribelli C, Brites D. (2000) Assessment of bilirubin toxicity to erythrocytes: implication in neonatal jaundice management. Eur. J. Clin. Invest. 30:239-47.

14. Rodrigues CMP, Solá S, Brito MA, Brites D, Moura JJG. (2002) Bilirubin directly disrupts membrane lipid polarity and fluidity, protein order, and redox status in rat mitochondria. J. Hepatol. 36:335-41.

15. Rodrigues CMP, et al. (2002) Perturbation of membrane dynamics in nerve cells as an early event during bilirubin-induced apoptosis. J. Lipid Res. 43:885-94.

16. Mayor F Jr, Díez-Guerra J, Valdivieso F, Mayor F. (1986) Effect of bilirubin on the membrane potential of rat brain synaptosomes. J. Neurochem. 47:363-69.

17. Tsakiris S. (1993) $\mathrm{Na}^{+}, \mathrm{K}^{(+)}$-ATPase and acetyl- cholinesterase activities: changes in postnatally developing rat brain induced by bilirubin. Pharmacol. Biochem. Behav. 45:363-68.

18. Brito MA, Brites D, Butterfield DA. (2004) A link between hyperbilirubinemia, oxidative stress and injury to neocortical synaptosomes. Brain Res. 1026:33-43.

19. Rodrigues CMP, Solá S, Brites D. (2002) Bilirubin induces apoptosis via the mitochondrial pathway in developing rat brain neurons. Hepatology. 35:1186-95.

20. Silva R, et al. (1999) Inhibition of glutamate uptake by unconjugated bilirubin in cultured cortical rat astrocytes: role of concentration and $\mathrm{pH}$. Biochem. Biophys. Res. Commun. 265:67-72.

21. Silva RFM, Rodrigues CMP, Brites D. (2002). Rat cultured neuronal and glial cells respond differently to toxicity of unconjugated bilirubin. Pediatr. Res. 51:535-41.

22. Falcão AS, Fernandes A, Brito MA, Silva RFM, Brites D. (2006) Bilirubin-induced immunostimulant effects and toxicity vary with neural cell type and maturation state. Acta Neuropathol. 112:95-105.

23. Fernandes A, Silva RFM, Falcão AS, Brito MA, Brites D. (2004) Cytokine production, glutamate release and cell death in rat cultured astrocytes treated with unconjugated bilirubin and LPS. J. Neuroimmunol. 153:64-75.

24. Grojean S, Koziel V, Vert P, Daval JL. (2000) Bilirubin induces apoptosis via activation of NMDA receptors in developing rat brain neurons. Exp. Neurol. 166:334-41.

25. Grojean S, Lievre V, Koziel V, Vert P, Daval JL. (2001) Bilirubin exerts additional toxic effects in hypoxic cultured neurons from the developing rat brain by the recruitment of glutamate neurotoxicity. Pediatr. Res. 49:507-13.

26. McDonald JW, Shapiro SM, Silverstein FS, Johnston MV. (1998) Role of glutamate receptor-mediated excitotoxicity in bilirubin-induced brain injury in the Gunn rat model. Exp. Neurol. 150:21-9.

27. Brito MA, Silva RFM, Brites D. (2006) Bilirubin toxicity to human erythrocytes: a review. Clin. Chim. Acta. 374:46-56.

28. Sharma R, Premachandra BR. (1991) Membranebound hemoglobin as a marker of oxidative injury in adult and neonatal red blood cells. Biochem. Med. Metab. Biol. 46:33-44.

29. Brito MA, et al. (2008) Bilirubin injury to neurons: contribution of oxidative stress and rescue by glycoursodeoxycholic acid. Neurotoxicology. 29:259-69.

30. Brito MA, et al. (2008) Unconjugated bilirubin differentially affects the redox status of neuronal and astroglial cells. Neurobiol Dis. 29:30-40.

31. Vaz AR, et al. (2010) Bilirubin selectively inhibits cytochrome $c$ oxidase and induces apoptosis in immature cortical neurons: assessment of the protective effects of glycoursodeoxycholic acid. J. Neurochem. 112:56-65.

32. McDonagh AF. (1979) Bile pigments: bilatrienes and 5,15 biladienes. In: The Porphyrins. Dolphin D (ed.) Academic Press, New York, pp. 294-491. 
33. Silva RFM, et al. (2006) Dissociated primary nerve cell cultures as models for assessment of neurotoxicity. Toxicol. Lett. 163:1-9.

34. Fernandes A, et al. (2009) Bilirubin as a determinant for altered neurogenesis, neuritogenesis, and synaptogenesis. Dev. Neurobiol. 69:568-82.

35. Wang MJ, et al. (2004) c-Jun N-terminal kinase and, to a lesser extent, p38 mitogen-activated protein kinase regulate inducible nitric oxide synthase expression in hyaluronan fragmentsstimulated BV-2 microglia. J. Neuroimmunol. 146:50-62.

36. Dringen R. (2000) Metabolism and functions of glutathione in brain. Prog. Neurobiol. 62:649-71.

37. Butterfield DA, Lauderback CM. (2002) Lipid peroxidation and protein oxidation in Alzheimer's disease brain: potential causes and consequences involving amyloid beta-peptide-associated free radical oxidative stress. Free Radic. Biol. Med. 32:1050-60.

38. Karageorgos N, et al. (2006) Effect of $\mathrm{N}$-acetylcysteine, allopurinol and vitamin $\mathrm{E}$ on jaundice-induced brain oxidative stress in rats. Brain Res. 1111:203-12.

39. Cesaratto L, et al. (2007) Bilirubin-induced cell toxicity involves PTEN activation through an APE1/Ref-1-dependent pathway. J. Mol. Med. 85:1099-112.

40. Carmagnol F, Sinet PM, Rapin J, Jerome H. (1981) Glutathione-S-transferase of human red blood cells; assay, values in normal subjects and in two pathological circumstances: hyperbilirubinemia and impaired renal function. Clin. Chim. Acta. 117:209-17.

41. Hoffman DJ, et al. (1996) The in vivo effect of bilirubin on the N-methyl-D-aspartate receptor/ion channel complex in the brains of newborn piglets. Pediatr. Res. 40:804-8.

42. Boveris A, Alvarez S, Navarro A. (2002) The role of mitochondrial nitric oxide synthase in inflammation and septic shock. Free Radic. Biol. Med. 33:1186-93.

43. Geiger AS, Rice AC, Shapiro SM. (2007) Minocycline blocks acute bilirubin-induced neurological dysfunction in jaundiced Gunn rats. Neonatology. 92:219-26.

44. Lin S, et al. (2005) Minocycline blocks bilirubin neurotoxicity and prevents hyperbilirubinemiainduced cerebellar hypoplasia in the Gunn rat. Eur J. Neurosci. 22:21-7.

45. Day RL. (1954) Inhibition of brain respiration in vitro by bilirubin: reversal if inhibition by various means. Am. J. Dis. Child. 88:504-6.

46. Ernster L, Zetterström R. (1956) Bilirubin, an uncoupler of oxidative phosphorylation in isolated mitochondria. Nature. 178:1335-7.

47. Rodrigues CMP, Solá S, Silva R, Brites D. (2000) Bilirubin and amyloid- $\beta$ peptide induce cytochrome $c$ release through mitochondrial membrane permeabilization. Mol. Med. 6:936-46.

48. Brito MA, et al. (2007) Oxidative stress and disruption of the nervous cell. In: Focus on Brain Research. Resch CJ (ed.) Nova Science Publishers, Inc., New York, pp. 1-33.
49. Hankø E, Hansen TWR, Almaas R, Paulsen R, Rootwelt T. (2006) Synergistic protection of a general caspase inhibitor and MK-801 in bilirubininduced cell death in human NT2-N neurons. Pediatr Res. 59:72-7.

50. Shapiro SM, Sombati S, Geiger A, Rice AC. (2007) NMDA channel antagonist MK-801 does not protect against bilirubin neurotoxicity. Neonatology. 92:248-57.

51. Seidman DS, et al. (1991) Neonatal hyperbilirubinemia and physical and cognitive performance at 17 years of age. Pediatrics. 88:828-33.

52. Dalman C, Cullberg J. (1999) Neonatal hyperbilirubinaemia- a vulnerability factor for mental disorder? Acta Psychiatr. Scand. 100:469-71.

53. Schousboe A, Waagepetersen HS. (2005) Role of astrocytes in glutamate homeostasis: implications for excitotoxicity. Neurotox. Res. 8:221-5.

54. Gordo AC, Falcão AS, Fernandes A, Brito MA, Silva RFM, Brites D. (2006) Unconjugated bilirubin activates and damages microglia. J. Neurosci. Res. 84:194-201. 